\title{
SOME PECULIARITIES OF CREATION (UPDATING) OF DIGITAL TOPOGRAPHIC MAPS FOR THE SEAMLESS TOPOGRAPHIC DATABASE OF THE MAIN STATE TOPOGRAPHIC MAP IN UKRAINE
}

Nadiia Lazorenko-Hevel ${ }^{1}$, Yurii Karpinskyi ${ }^{1}$, Danylo Kin ${ }^{1}$

${ }^{1}$ Department of Geoinformation system and photogrammetry, Kyiv National University of Construction and Architecture, 31 Povitroflotsky Ave, Kyiv, 03037, Ukraine

Correspondence to: Nadiia Lazorenko-Hevel ${ }^{1}$ (nadiialg@gmail.com)

https://doi.org/10.31490/9788024845050-8

\begin{abstract}
The article examines the peculiarities of creation (updating) digital topographic maps of the scale 1:50 000 for the Main State Topographic Map of Ukraine for creation and maintaining the seamless topographic database for national needs, which is located on the Geoportal to ensure the development of the National Spatial Data Infrastructure (NSDI) in Ukraine. Several special problems were identified along with the implementation of standard processes of vectorization of topographic maps, the solution of which helped to increase the intellectual level of the data, efficiency of production process management and automation of quality control. The peculiarities were proposed by the authors: creation virtual features that do not belong to the real world, such as watercourses, blocks, boundaries of settlements; development of the Geoportal project monitoring and support system for automation of the production process and exchange of information between project participants; implementation of automated quality control of digital topographic maps.
\end{abstract}

Keywords: National Spatial Data Infrastructure (NSDI), topographic mapping, Main State Topographic Map, seamless topographic database, quality control.

\section{INTRODUCTION}

The current state of provision of the territory of Ukraine with topographic maps of the entire scale is characterized as critical because the works on the national topographic mapping of the entire country have not been carried out for a long time [Karpinskyi \& LazorenkoHevel, 2018, Karpinskyi \& Lazorenko-Hevel, 2020]. Adoption of the Law of Ukraine "On National Infrastructure of Geospatial Data" on 13th April 2020 and its implementation emphasized the urgent need and urgency in creating the Core Reference datasets, which form a unified digital coordinate-spatial basis for production, integration and other activities with different thematic geospatial datasets [The NSDI Law of Ukraine, 13.04.2020].

The research is related to the implementation of the Ukrainian-Norwegian project "Maps for good land governance" (hereinafter - project).

The seamless topographic database of the Main State Topographic Map is being created for the first time in Ukraine within the framework of the project, the input data of which are the updated digital topographic maps of the scale 1:50 000, which will public on the Geoportal for providing access to the Core Reference datasets of the national level of the 
NSDI of Ukraine, metadata and GIS services on the Internet. There is one of the main peculiarities of the created digital topographic maps of the scale 1:50 000 that they are hybrid because of the updating of features with clear contours (networks of roads, streets, driveways, blocks and houses, power lines (voltage over $35 \mathrm{kV})$ ) is performed with detail and accuracy of the scale 1:10 000, and updating all other features - with an accuracy of 1:50 000. Certain peculiarities were defined by authors in the process of creation (updating) digital topographic maps of the scale 1:50 000/1:10 000: automated creation of new virtual and associated features, use rules of the digital description of topographic features and rules of topological relations between features of a digital topographic map, providing of automated quality control of updated digital topographic maps, development the Geoportal project monitoring and support system for production process automation, control of implementation and simplification of access to information exchange between project participants.

The purpose of the article is to research the peculiarities of creation (updating) of digital topographic maps of the scale 1:50 000/1:10 000 which would satisfy the requirements for the development of the seamless Topographic Database of the Main State Topographic Map.

\section{RESULTS}

The virtual features of digital topographic maps. The new requirements to create topographic database defined the need to create new features that do not belong to realworld features [Jakobsson, 2006; Lüscher, 2011], the so-called virtual, for updating digital topographic maps for example watercourses. Watercourses are created automatically products of equidistant - the lines equidistant from the banks of rivers and waters, which are present by a segmental-nodal model and create tree-networks (rivers, inflowing streams of the first and second rank, etc. with possible contours around the islands) (Fig. 1). The watercourses will be used during the creation of the seamless topographic database for the construction of a model of an aggregate hydrographic network. The associated complex features are created at the stage of updating digital topographic maps, for example, blocks and boundaries of the settlements due to the automated production of equal distances (streets) and buffer zones around the different type of streets (Fig. 2).

The Geoportal project monitoring and support system. The authors and the staff of State Enterprise "Research Institute of Geodesy and Cartography" were developed the Geoportal project monitoring and support system for production process automation, control of implementation and simplification access to information exchange between project participants, which includes the following modules: register of the map sheets, register of executors and cartographers; the subsystem of the Executors' personal cabinet; subsystem of cartographic material delivery; the subsystem of control works delivery terms; online maps of performing works/map sheets. Figure 3 shows a cartogram of the status of works by executors.

Automated quality control. The 141 rules of topological relations between the spatial 
features are formulated in ArcGIS to ensure the correctness of the creation (updating) of digital topographic maps, editing spatial features based on topographic codes, attributes of spatial feature classes: Must Be Larger Than Cluster Tolerance; Must Not Overlap; Must Not Have Gaps etc. The automated quality control of updated digital topographic maps is performed using ArcGIS 10.5 and the software package "Validate", which was created using the Python programming language to verify logical consistency, compliance with the rules of topological relationships between features on the map, availability and content of metadata, edge matching of adjacent map sheets [Lazorenko-Hevel, Kin, Karpinskyi, 2020)].

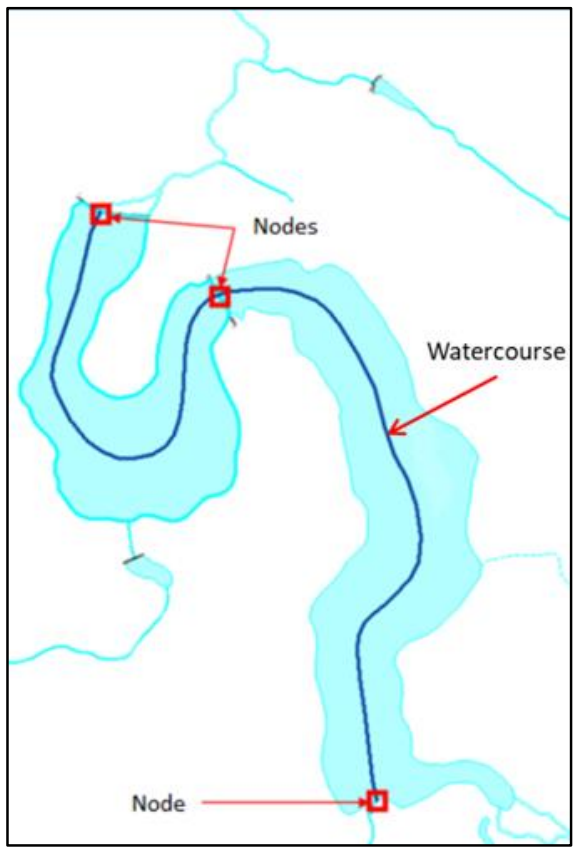

Fig. 1. Example of the vector models of watercourses

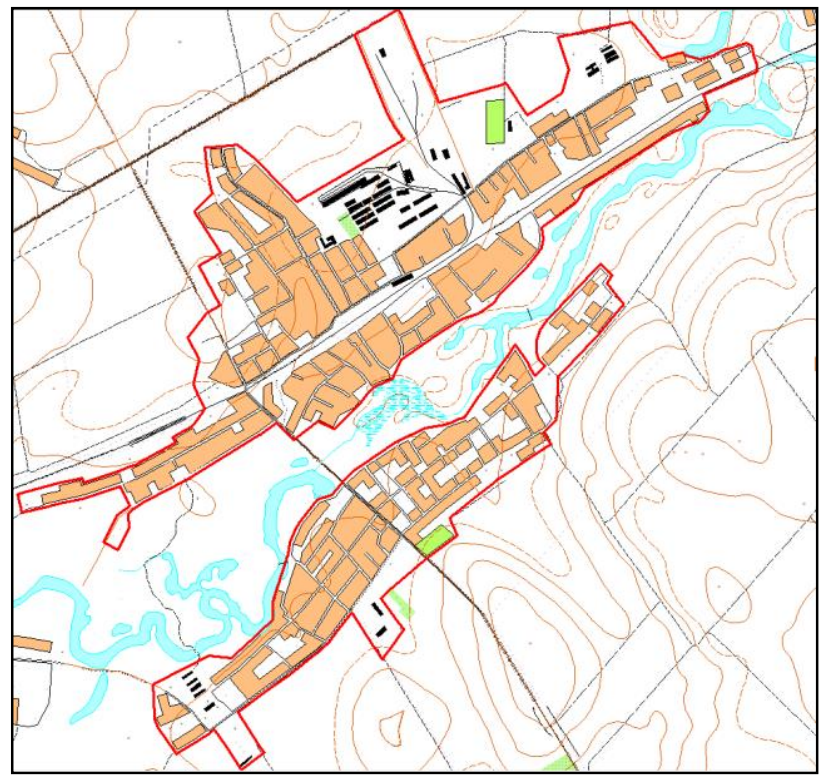

Fig. 2. Example of the vector models of blocks and settlement

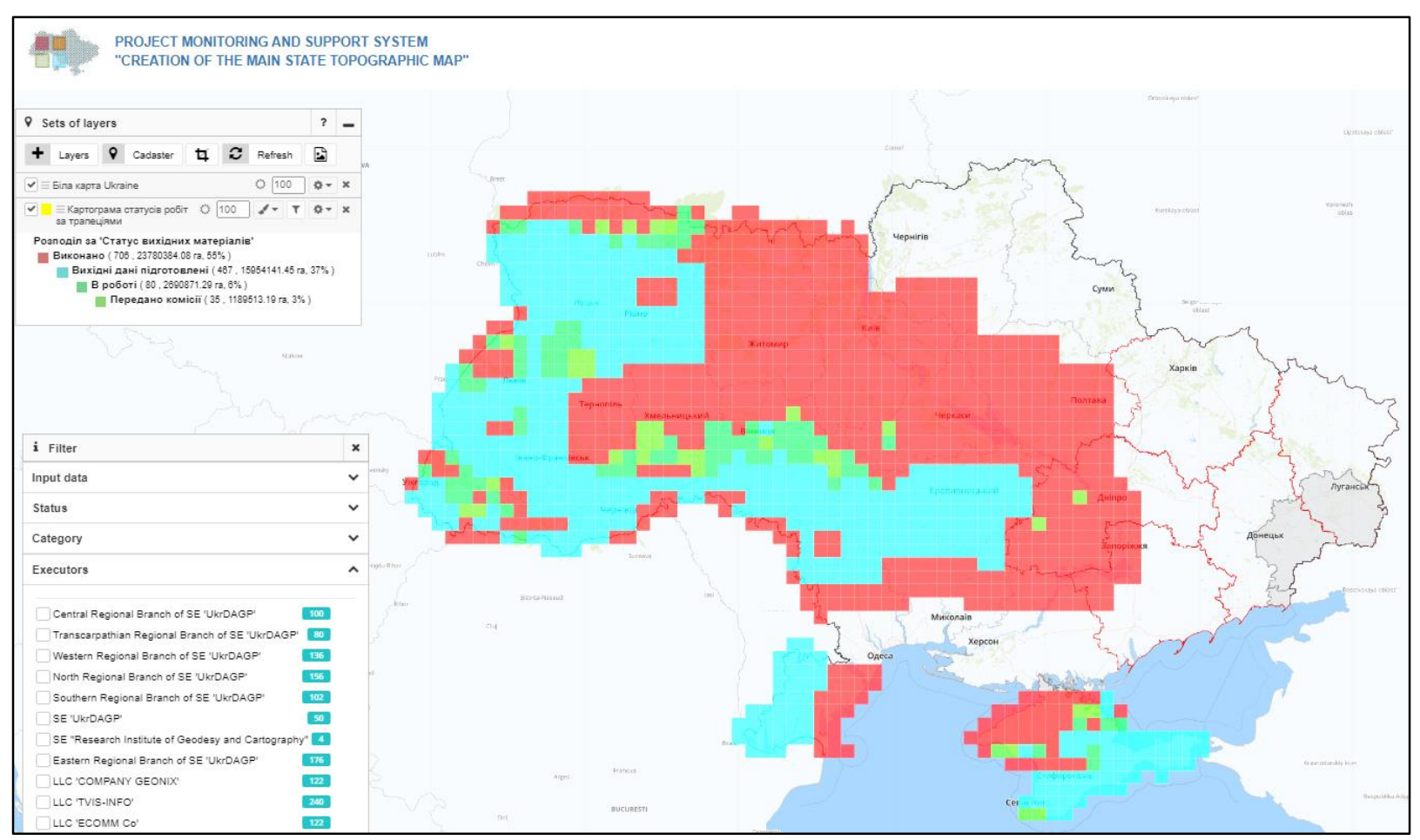


Fig. 3. The cartogram of the status of works by executors

Besides, the process of estimation the accuracy of the planned position of features is automated using the Python programming language by comparing 20 coordinates of control points which were determined by the orthophoto with the coordinates of the corresponding points of the updated digital topographic map and calculating the root mean square error (RMSE) of the feature. The root mean square error of the updated digital topographic map is calculated by the formula (1):

$M=\sqrt{M_{f}^{2}+M_{S}^{2}}$

where: $M_{s}$ is the RMSE of the orthophoto of the scale 1: 10000 , which is $0.5 \mathrm{~mm}$ on the scale of the orthophoto (5 $\mathrm{m}$ - on the ground); $M_{s}$ is the RMSE of the position of the control point of the digital topographic map.

The RMSE of the control points of the digital topographic map $M_{s}$ is calculated by the formula (2):

$M_{s}=\sqrt{M_{x}^{2}+M_{y}^{2}}$

where: $M_{x}, M_{y}$ are the RMSEs of the position of control points in the coordinates $\mathrm{X}$ and $\mathrm{Y}$. The RMSE of the position of control points in the coordinates $X$ and $Y$ is calculated by the formulas $(3,4)$ :

$M_{x}=\sqrt{\frac{\sum_{i}^{n} \Delta_{x i}^{2}}{n}} ; M_{y}=\sqrt{\frac{\sum_{i}^{n} \Delta_{y i}^{2}}{n}}$

where: $\Delta x_{i}$ and $\Delta y_{i}$ are the increase of coordinates of $X$ and $Y$.

Figure 4 shows an estimation of accuracy for one of the updated digital topographic map M-36-51-B. In the same way, 1288 updated map sheets were estimated for the territory of Ukraine within the project.

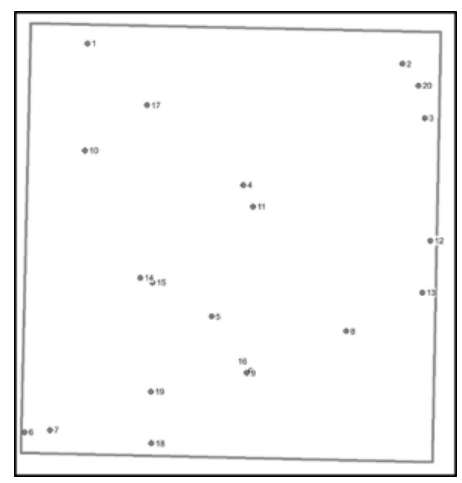

\begin{tabular}{|c|c|c|c|c|c|c|c|c|c|}
\hline № & Xmap & Ymap & Xortho & Yortho & $\Delta \mathbf{X i}$ & $\Delta \mathbf{Y i}$ & $\Delta \mathbf{X}^{2} \mathbf{i}$ & $\Delta \mathbf{Y}^{2} \mathbf{i}$ & RMSE \\
\hline 1 & 6359724.668 & 5598026.534 & 6359724.759 & 5598025.959 & 0.09 & -0.58 & 0.01 & 0.33 & 0.58 \\
\hline 2 & 6368050.944 & 5597674.428 & 6368048.028 & 5597671.872 & -2.92 & -2.56 & 8.50 & 6.53 & 3.88 \\
\hline 3 & 6370730.306 & 5597660.42 & 6370728.62 & 5597660.239 & -1.69 & -0.18 & 2.84 & 0.03 & 1.70 \\
\hline$\ldots . .$. & & & & & & & & & \\
\hline 19 & 6358439.707 & 5580346.563 & 6358440.396 & 5580346.358 & 0.69 & -0.20 & 0.47 & 0.04 & 0.72 \\
\hline 20 & 6369449.545 & 5589756.171 & 6369451.761 & 5589755.556 & 2.22 & -0.61 & 4.91 & 0.38 & 2.30 \\
\hline$\Sigma$ & & & & & 14.58 & -14.90 & 61.14 & 42.20 & 40.21 \\
\hline & & & & $\mathrm{Mx}=$ & 1.75 & $\mathrm{~m}$ & & & \\
\hline & & & & $\mathrm{My}=$ & 1.45 & $\mathrm{~m}$ & & & \\
\hline & & & & $\mathrm{Ms}=$ & 2.27 & $\underline{m}$ & & & \\
\hline & \multirow{3}{*}{\multicolumn{3}{|c|}{$\begin{array}{l}\text { Root-mean-square error (RMSE) } \\
\text { Mean error }\end{array}$}} & & & & & & \\
\hline & & & & $M=$ & 5.49 & m & & & \\
\hline & & & & $\theta=$ & 4.39 & $\mathrm{~m}$ & & & \\
\hline
\end{tabular}


Fig.4. Estimation of accuracy of the updated digital topographic map M-36-51-B

\section{CONCLUSIONS}

The creation of the seamless topographic database formulates the need to increase the intellectual level of creation spatial data of topographic features. So, the authors offer some peculiarities for the classical technology of creation (updating) digital topographic maps: creation virtual features that do not belong to the real world, such as watercourses, blocks, boundaries of settlements; development of the Geoportal project monitoring and support system for automation of the production process and exchange of information between project participants; implementation of automated quality control of digital topographic maps. Updated digital topographic maps will be used for the formation of the Main State Topographic Map as a set of interconnected structured geospatial data in the topographic database and arrangement it on the Geoportal for the development of NSDI in Ukraine.

\section{REFERENCES}

Jakobsson, A. (2006) On the Future of Topographic Base Information Management in Finland and Europe. Doctoral dissertation. Helsinki University of Technology, p.180 Retrieved from: http://lib.tkk.fi/Diss/2006/isbn9512282062/isbn9512282062.pdf.

Karpinskyi, Yu. and Lazorenko-Hevel, N. (2018) Application of topographic plans in the conditions of the development of national spatial data infrastructure, Mistobuduvannya ta terytorial'ne planuvannya, 68 , p. 712-724. Retrieved from: http://nbuv.gov.ua/UJRN/MTP $201868 \quad 85$.

Karpinskyi, Yu. and Lazorenko-Hevel, N. (2020) Topographic mapping in the National Spatial Data Infrastructure in Ukraine. E3S Web of Conferences. 171, p.1-6. Retrieved from: https://doi.org/10.1051/e3sconf/202017102004.

Lazorenko-Hevel N., Kin D. \& Karpinskyi Yu. (2020) Some aspects of the edge matching method of digital topographic maps in the scale of 1:50 000 for creation the Main State Topographic Map. European Association of Geoscientists \& Engineers. Conference Proceedings, International Conference of Young Professionals «GeoTerrace-2020», Dec 2020, Volume 2020, p.1-5. Retrieved from: https://doi.org/10.3997/2214$\underline{4609.20205758}$

The Law of Ukraine "On the National Spatial Data Infrastructure" (bill No. 2370), 13.04.2020. Retrieved from: http://w1.c1.rada.gov.ua/pls/zweb2/webproc34? $i d=\& p f 3511=67268 \&$ pf35401=525603 $(09.01 .2020)$.

Lüscher, P. (2011) Characterising urban space from topographic databases: cartographic pattern recognition based on semantic modelling. Zurich Open Repository and Archive, University of Zurich.

Retrieved from: https://www.zora.uzh.ch/id/eprint/164120/1/20121448.pdf. 